This is a postprint version of the following published document:

Jara, M., Paolini, D. and Tena, J. de D. (2015). Management efficiency in football: an empirical analysis of two extreme cases. Managerial and Decision Economics, v. 36, n. 5, pp. 286-298. Avalaible in: http://dx.doi.org/10.1002/mde.2668

(c) Wiley 


\title{
Management Efficiency in Football: An Empirical Analysis of Two Extreme Cases
}

\author{
Miguel Jara ${ }^{\mathrm{a}}$, Dimitri Paolini ${ }^{\mathrm{b}, \mathrm{c}}$ and Juan de Dios Tena Horrillo ${ }^{\mathrm{c}, \mathrm{d}, *}$

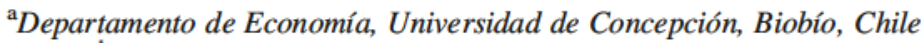 \\ ${ }^{\mathrm{b}}$ CRENoS and DISea, Università di Sassari, Sassari, Italy \\ ${ }^{\mathrm{c}}$ CORE, Université catholique de Louvain, Louvain La Neuve, Belgium \\ ${ }^{\mathrm{d}}$ Department of Statistics and Instituto Flores de Lemus, Universidad Carlos III, Madrid, Spain
}

\begin{abstract}
Analysis of managerial efficiency in sport economics typically focuses on evaluating coach decisions instead of assessing the organization as a whole. This paper studies the relative importance of variables related to power and managerial decisions by estimating stochastic production frontiers models for the Chilean and Italian football leagues. We find that historical and geographical variables intended to capture market size play their expected roles in both Italy and Chile. However, the degree of technical inefficiency is lower magnitude in Chile. This difference could be due to a smaller market size and/or to financial constraints faced by small clubs in this country.
\end{abstract}

\section{INTRODUCTION}

The empirical analysis of the factors, which determine technical inefficiencies in the sports industry has been a topic of intense research; see, for example, Hofler and Payne (2006), Kahane (2005) and Simmons and Frick (2008). Technical efficiency is defined as the effectiveness with which a given endowment of input factors is used to produce an output. Therefore, a firm can be considered to be technically efficient if it generates the maximum output from a given quantity of inputs. In the existing studies, the focus is typically either on the ability of one layer of management (the coach) to extract the best possible performance from the players given his budget (Kahane, 2005 and Simmons and Frick, 2008) or on the role of team strategy (Hofler and Payne, 2006). These studies tend not

*Correspondence to: CRENoS and DISea, Università di Sassari, Sassari, Italy and Department of Statistics and Instituto Flores de Lemus, Universidad Carlos III, Madrid, Spain. E mail: jtena@est econ.uc3m.es to be focus on the overall ability of the organization to transform its potential power over resources to the best possible outcome.

Estimating the overall efficiency of different organizations in dealing with their resources is important in the fields of industrial organization and management studies. However, it is usually not an easy task, mainly because of the difficulties in obtaining good proxies for some unobservable variables, such as the 'power' or 'performance' of the different firms in a given industry. However, in the analysis of sport, these problems may be overcome. Results on the field provide a good measure of output that are public information, and, even where information on inputs is not publically observed, observable club characteristics may be sufficiently well-correlated with clubs' command over resources to serve the purpose of testing for efficiency. For example, Buraimo et al. (2007) report high correlation, for the 92 clubs in English professional football, between the potential of a club (as represented by variables capturing its geography and history) and both the club's revenue and its 
ranking in the league. This is consistent with the central proposition of the most influential theoretical model in sports economics, the two-team league model of El-Hodiri and Quirk (1971), which suggests that large market clubs will dominate small market clubs because they generate greater revenue and hire better players. For example, a club may be located in a large city and have won many trophies in the past. This 'big' club would therefore have a larger fan and revenue base than its rivals and greater power in the player labor market. If both clubs are managed efficiently, the 'big' club is expected to win more matches than the small club.

This paper presents an empirical analysis of the presence of $x$-inefficiency in the top divisions of the Chilean and Italian football leagues through the estimation of stochastic production frontiers. The comparison between levels and efficiency in the two leagues is especially interesting given that, compared with the Italian league, clubs in the Chilean league face a lower demand and is in principle more likely to be affected by financial restrictions at the national level that prevent them from achieving the highest possible performance. ${ }^{1}$ Moreover, the comparative analysis of these two extreme cases is a novel aspect of our paper compared with related literature on sport, which usually focuses on a single national league. The selection of the Chilean league is motivated by the fact that the structure of the Chilean competition has been relatively stable and all the required information was publicly available during the period of analysis. This is not the case of other modest national leagues in Latin America, such as the Peruvian or the Mexican competitions. The selection of the Italian league is because it is one of the top competitions of the world in terms of media attention and trophies both at the national and club levels.

The main hypothesis to be tested is whether, unlike to the Italian league, performance in the Chilean league is mainly determined by a smaller market size and/or to financial constraints, and, as a result of this, managerial decisions play a less significant role in the Chilean league. In particular, our econometric specification relates team performance to a set of power indicators (history and past results), whereas stochastic deviations of this function can be explained by managerial decision variables. Then, this estimation is used for a comparative discussion of team efficiency between, instead of within, leagues. Although it is very difficult, if not impossible, to classify each of the football clubs in the sample according to their size and complexity, it can be generally accepted that teams in the Chilean league are smaller and simpler enterprises than teams in the Italian league. ${ }^{2}$

To preview, we find evidence of technical inefficiencies in both the Chilean and the Italian leagues. However, an important difference is that, in the Italian league, a significant share of team performance is due to stochastic shocks related to the efficiency of club management; by contrast, stochastic elements do not play a significant role in the Chilean league. This difference could be explained by the presence of simpler and smaller clubs in the Chilean league that could be because of the different size of the market and/or to financial constraints faced by small clubs in that country.

In the next section of the paper, we provide some theoretical insights about the relationship between institutional complexity and managerial effort. Section 3 presents and describes the variables used in the analysis, and Section 4 explains the econometric approach used to estimate the impact of resource variables and technical inefficiencies on output in Chilean and Italian football and discusses the results of the estimation. Conclusions are drawn in Section 5.

\section{GUIDANCE FROM THEORY}

In this section, we develop intuition about the relationship between managerial effort and institutional complexity. In order to do this, we adopt the framework of Paolini and Tena (2012) that is itself an extended version of other two clubs models in the field of sport economics, El-Hodiri and Quirk (1971), Haan et al. (2002) and Késenne (2007).

In this framework, there are two clubs $(i=1,2)$, which play a series of matches against each other. Each of the clubs has simultaneously to decide its level of capital $\left(k_{i}\right)$ and managerial effort $\left(s_{i}\right)$ in order to maximize its profit function $V_{i}\left(k_{i}, s_{i}\right)=\Pi_{i}\left(k_{i}, s_{i}\right)-C_{i}\left(k_{i}, s_{i}\right)$. These two variables have a positive impact on revenue $\left(\Pi_{i}\right)$ as capital and effort increase the probability of winning but, on the other hand, it is increasingly more costly $\left(C_{i}\right)$ for a club to augment its level of capital and managerial effort. The latter effect is more important because while the revenue of the clubs is bounded and subject to decreasing returns, the cost can be increased to infinity. This is a usual and realistic assumption in theoretical models and ensures that an equilibrium level for both variables exists; see Mas-Colell et al. (1995), Chapter 5.

The key assumption of the model states that $\frac{\partial C_{i}\left(k_{i} s_{i}\right)}{\partial\left(k_{j}\right)}>0$, with $i \neq j$ : the cost (of capital) by a certain 
club is positively affected by the quantity invested by its rival. The reason for this is that if a club invests heavily in attracting most of the star players, football fans and media attention, it will leave less of the market to its rival.

Under these conditions, the equilibrium of the model states the following: (1) there is an optimal level of managerial effort $\left(\left(s^{*}\right)\right)$ given capital investment for each club; and (2) the equilibrium levels of capital and managerial effort of each clubs are inversely related: $\frac{\partial s_{i}^{*}}{\partial k_{i}^{*}}<0$.

In this framework, it becomes interesting to analyze how managerial effort in each club reacts to changes in capital. For example, let us assume that one of the clubs (e.g., $j$ ) suddenly increases its capital $\left(k^{*}\right)$. This will make capital more expensive for the rival club, and hence it will react by reducing its level of capital, $\frac{\partial k_{i}^{*}}{\partial k_{j}^{*}}<0$, and increasing its managerial effort, $\frac{\partial s_{i}^{*}}{\partial k_{j}^{*}}>0$, due to the negative relationship between these two variables. A relevant implication of this is that clubs with low capital, either because of a reduced share of the market or due to restrictions in the financial market, will react by increasing its level of managerial effort. $^{3}$

According to this hypothesis, it is relevant to analyze the importance of managerial variables in two extreme cases, one in which the level of capital by different clubs is clearly constrained by the size of the market (the Chilean league) and another with big and complex clubs (the Italian league). The prediction of the model is the clubs' performance in the Chilean league is mainly determined by resources allocation that is potentially constrained by the size of the market by financial restrictions. Therefore, managers play a less important role in this league than in the Italian competition where clubs face less severe restrictions, and it is not the availability of inputs, but the way they are combined to produce a certain level of output what makes the difference.

Of course, as discussed in the introduction, this analysis requires taking consideration of the total endowment of the clubs. In our particular framework, this is a much more broadly measure than the budget on players that is very likely to be endogenously affected by performance expectations. Moreover, it does not include all the available information about capital of the club. Especially in professional football, this measure of capital is largely intangible as it includes branding. However, it is reasonable to assume that this intangible capital is highly correlated with a set of proxy variables that should include stadium capacity and the history of the club (see Buraimo et al. (2007)). In addition, we also include in the group of endowment variables the size of the city as it could be considered as an indicator of the potential number of supporters of the club. For example, in the case of Italy, the Istituto Nielsen reports the number of supporters ('tifosi') for each Italian club in Series A during 2008. The clubs with the most supporters were Juventus, F.C. Internazionale di Milano, A.C. Milan and Roma. These clubs belong to the three biggest cities in Italy, Turin, Milan and Rome. The clubs with fewest supporters correspond to small cities such as Verona, Lecce and Siena. We do not have such detailed information about the number of supporters for clubs in the Chilean league, but it can be clearly observed that clubs from Santiago, the biggest city in the country, typically win the Chilean national league.

In the remaining of this paper, we estimate and analyze a stochastic production function for the top league competitions in Chile and Italy. Consistent with the framework just discussed in this section, the variables considered in the estimation of the stochastic production function are the set of inputs related to the resources of clubs that cannot be modified in the short run and technical decision variables, which refer to the composition of the squad and manager features. This is a novel aspect compared with the related literature in sport economics (discussed in the introduction), which typically focuses on the evaluation of the efficiency of coaches and/or club players given the wage budget of the club. Unlike this literature, our interest is in the evaluation of managerial efficiency, controlling for the amount of resources of the whole organization. The null hypothesis is that input variables should matter more (and therefore, explain a higher proportion of outcome, i.e., results) in the Chilean league because the capital of clubs in this competition is restricted by the size of the market, and possibly they are more likely to face financial constraints. Also, technical decision variables should explain a higher proportion of results in Italy.

\section{DATA ON THE ITALIAN AND CHILEAN FOOTBALL LEAGUE}

For the Italian league, our season-level variables relate to the period from $1992 / 1993$ to $2007 / 2008$. During the sample period, there were 18 teams before 2004/ 2005 and 20 teams from 2004/2005 in the Italian Series A. Before season 2004/2005, four teams were 
promoted and relegated and three teams afterwards. The best four teams qualify for the Champions League, whereas teams can qualify for the Europa League either by winning the Italian Cup or by ending up in the fifth or sixth position in the national league.

In the case of Chile, our database covers the period from 1993 to 2008 . The first division was composed of 16 teams until 2004 and since then 20,19, 21 and 20 for seasons 2005, 2006, 2007 and 2008, respectively. Each season is composed of two sequential competitions as follows: Opening ('Apertura') and Closing ('Clausura'). The champion of each tournament and the best second ranked automatically qualified for the most important international competition at the club level in South America, Copa Libertadores de America.

The following variables are considered in both cases:

Output (performance) measure

(i) Number of points divided by the maximum available for the $i$ th team in season $t\left(y_{i, t}\right)$. Although during the sample period the number of points awarded for a victory changed from two to three, in season 1995/1996 for the Italian league and 1996 for the Chilean league, to make the performance measure consistent across seasons, we computed it on the basis of three points for a win throughout the whole period. A dummy variable is used in the estimation to represent the seasons when three points was actually employed as the change in incentives was likely to have influenced the pattern of results. Simmons and Frick (2008) followed a similar procedure for Germany.

Resource variables

(ii) International tournament $\left(x_{1, i, t}\right)$ : dummy that takes the value 1 when club $i$ was playing in that season's European Champion League (Italy) or Copa de Libertadores (Chile) at season $t$.

(iii) Stadium capacity $\left(x_{2, i, t}\right)$.

(iv) Population size of the city (where the team plays its home games) $\left(x_{3, i, t}\right)$.

(v) Champion in previous years $\left(x_{4, i, t}\right)$ : a weighted sum of the number of national league trophies in the previous 3 years. The weights were $\left(1 / t^{2}\right)$ where $t$ was 1 for the previous season, 2 for the season before and 3 for the season before that.

(vi) Performance in previous years $\left(x_{5, i, t}\right)$ : a weighted measure of the inverse of the ranking of each team in each of the top division competitions in the preceding 3 years. Performance is equal to
0 in case a team has been in the second division. Weights are defined similarly to the previous variable.

Of course, the choice of the three previous years in the last two variables is to an extend arbitrary. However, this is not a relevant decision because there is a strong inertial component in clubs' performance and recent results are more informative about the current club's position than distant result. In fact, some experiments not explicitly reported here, but available from the authors under request, show that our results are robust to the consideration of five (instead of three) previous years as a measure of performance.

(vii) Capital city $\left(x_{6, i, t}\right):$ a dummy variable that takes the value 1 when the team plays in the capital of the country, Santiago de Chile in the case of Chile and Rome in the case of Italy.

Technical decisions variables

(viii) Total number of players $\left(z_{1, t, t}\right)$ : total number of footballers in each squad.

(ix) Number of foreigners $\left(z_{2, i, t}\right)$ : total number of foreigners for each club.

(x) \% goalkeepers $\left(z_{3, i, t}\right)$ : share of goalkeepers in the squad.

(xi) \% defenders $\left(z_{4, i, t}\right)$ : share of defenders in the squad.

(xii) \% midfielders $\left(z_{5, i, t}\right)$ : share of midfielders in the squad.

(xiii) Number of high scoring players $\left(z_{6, i, t}\right)$ : number of players at each club who had scored more than 20 goals in the previous season. Of course, this variable could be affected by many events that were not fixed through time such as injuries, the presence of international competitions at the club or national level and the number of teams in the league. However, it is difficult to take all these events into account based on subjective appreciation, and because of this, we do not change the definition of this variable through the sample. We acknowledge this as a potential weakness of our analysis, to be explored in future research.

(xiv) Manager quality $\left(z_{7, i, t}\right)$ : proportion of matches won during the career of the manager of the club prior to season $t$ in his respective league (Chile or Italy).

(xv) Manager experience $\left(z_{8, i, t}\right)$ : number of years that the coach of the team had been involved in 
managerial activities in his respective league (Chile or Italy).

(xvi) Foreign manager $\left(z_{9 i, t}\right)$ : a dummy variable that takes the value 1 when the manager is a foreigner and 0 otherwise.

All these variables were collected for the beginning of the season to avoid potential endogeneity problems.

Table 1 displays some descriptive statistics of these variables. The average values for many of the variables are very similar in Italy and Chile. The most relevant differences between the two leagues can be observed in stadium capacity, which on average takes higher values in Italian football. Also, size of the city reveals that top division teams are more concentrated in the big cities for the Chilean football league (mainly in the capital Santiago de Chile), whereas in Italy there are top football teams in relatively small cities. This is the case, for example, in Atalanta, Livorno, Empoli, Siena and Udinense. Some important differences also relate to the number of foreign players and managers in the two countries. As expected, the Italian league attracts a higher number of foreigners.

\section{EMPIRICAL RESULTS}

The model of stochastic frontier production functions was initially developed by Aigner et al. (1977) and Meeusen and van den Broeck (1977) and extended to panel data by Battese and Coelli (1995). The standard specification for a set of firms indexed by $i$ over a number of periods $t$ can be represented as

$Y_{i, t}=\alpha+\beta^{\prime} x_{i, t}+\left(v_{i, t}+v_{i, t}\right) i=1, \ldots, N ; t=1, \ldots, T$

where $Y_{i, t}$ is a measure of firm $i$ 's output at time $t, x_{i, t}$ is a vector of the inputs defined in the previous section, and $\beta$ is a vector of unknown coefficients to be estimated. A common practice in the literature is to take logs of variables $Y_{i, t}$ and $x_{i, t}$. However, here, we do not apply this transformation of the dependent variable as it is already defined as a ratio (points divided by maximum possible points in a season) ${ }^{4}$.

The remainder of the equation is an error term composed of two components: (1) $v_{i, t}$ is a random error term assumed to be $i i d \sim N\left(0, \sigma_{v}^{2}\right)$; and (2) $v_{i, t}$ is a nonnegative random error term that is assumed to be independent and to follow a normal distribution that is truncated at 0 and $i i d \sim N\left(m_{i, t}, \sigma_{v}^{2}\right)$. Mean inefficiency, $m_{i, t}$, is modeled as a function of various firm-level factors. Specifically,

$m_{i, t}=\delta^{\prime} z_{i, t}+w_{i, t}$

where $z_{i, t}$ is a vector of technical decisions undertaken by firm $i$ in period $t$, and $\delta$ is another vector of coefficients to be estimated. The error term is assumed to be iid $\sim N\left(0, \sigma_{w}^{2}\right)$ truncated at $-\delta$ ' $z_{i, t}$ for consistency with the assumption that $v_{i, t}$ is nonnegative and truncated at 0 .

Table 1. Descriptive Statistics

\begin{tabular}{|c|c|c|c|c|c|c|c|c|}
\hline & \multicolumn{4}{|c|}{ Italy } & \multicolumn{4}{|c|}{ Chile } \\
\hline & Average & Variance & Minimum & Maximum & Average & Variance & Minimum & Maximum \\
\hline Points divided by maximum & 0.472 & 0.020 & 0 & 0.851 & 0.471 & 0.017 & 0.144 & 0.833 \\
\hline Capital & 0.138 & 0.119 & 0 & 1 & 0.395 & 0.240 & 0 & 1 \\
\hline International tournament & 0.194 & 0.157 & 0 & 1 & 0.172 & 0.143 & 0 & 1 \\
\hline Stadium capacity (scale 1/100,000) & 0.005 & 0.000 & 0.001 & 0.008 & 0.003 & 0.000 & 0.001 & 0.053 \\
\hline Size of the city (scale 1/1000.000) & 0.091 & 0.007 & 0.007 & 0.271 & 0.190 & 0.044 & 0.001 & 0.467 \\
\hline Champion in previous years & 0.130 & 0.119 & 0 & 1.833 & 0.143 & 0.110 & 0 & 1.583 \\
\hline Performance in previous years & 0.909 & 0.094 & 0.121 & 1.539 & 0.928 & 0.080 & 0.333 & 1.521 \\
\hline Number of foreigners & 8.039 & 20.756 & 0 & 24 & 3.953 & 1.804 & 0 & 7 \\
\hline Total number of players & 25.836 & 11.575 & 17 & 36 & 26.219 & 18.836 & 18 & 43 \\
\hline$\%$ goalkeepers & 0.087 & 0.001 & 0.036 & 0.167 & 0.090 & 0.001 & 0.036 & 0.174 \\
\hline$\%$ defenders & 0.326 & 0.002 & 0.174 & 0.448 & 0.306 & 0.003 & 0.136 & 0.48 \\
\hline$\%$ midfielders & 0.370 & 0.003 & 0.227 & 0.538 & 0.376 & 0.004 & 0.214 & 0.545 \\
\hline$\%$ forwards & 0.217 & 0.003 & 0.095 & 0.44 & 0.228 & 0.002 & 0.12 & 0.423 \\
\hline Number of high scoring players & 1.190 & 0.639 & 0 & 4 & 0.974 & 1.301 & 0 & 7 \\
\hline Manager quality & 0.374 & 0.021 & 0 & 0.697 & 0.310 & 0.032 & 0 & 0.705 \\
\hline Manager experience & 2.224 & 2.772 & 1 & 13 & 3.957 & 14.653 & 0 & 17 \\
\hline Foreign manager & 0.138 & 0.119 & 0 & 1 & 0.330 & 0.222 & 0 & 1 \\
\hline New manager & 0.409 & 0.243 & 0 & 1 & 0.451 & 0.249 & 0 & 1 \\
\hline
\end{tabular}

${ }^{\mathrm{a}}$ For the Italian League, there is an unique case of a team with 0 points that correspond to Juventus in season 2005/2006 that was demoted to Serie $\mathrm{B}$ because of a match fixing scandal. 
The model presented in Equations (1) and (2) is estimated following the maximum likelihood method proposed by Battese and Coelli (1993) and made available in Coelli's (1996) computer program FRONTIER 4.1. The parameter $\gamma=\left(\sigma_{v}^{2}\right) /\left(\sigma_{v}^{2}+\sigma_{v}^{2}\right)$.takes values in $[0,1]$, and it is particularly important as it shows the proportion of the sum of the two error variances that is accounted by technical inefficiencies. When this parameter is not statistically different from 0 , then it is not possible to reject the null hypothesis of zero technical inefficiencies and the specification to estimate the production function should be a standard panel data econometric procedure.

As discussed in Section 1, because our focus is not specifically on the coach but on the efficiency of the organization as a whole, the production frontier is not estimated by relating performance to the quality of the playing staff at the club as proxied by its total wage bill. Another important reason for not including the wage bill in this study is that the size of the budget at each club was not available at all in the case of Chile; even for Italy, the figures for wage bills were probably unreliable either because clubs had an incentive to misreport or simply because complex bonus arrangements make it hard to represent a club's financial commitment with a single summary figure. ${ }^{5}$ Note also that, given their focus on coaching ability, the wage bill is properly taken as exogenous in the empirical models of Kahane (2005) and Simmons and Frick (2008) but its size will in fact be influenced by expected team performance that year.

Accordingly, our resource variables, the $x_{i, t}$ in Equation (1), seek to represent factors from the geography and history of the club that should, collectively, determine its power to command resources. The task of management in the organization is to translate power into output (points). Decisions are, of course, taken at a number of levels in the club. In the stylized club we have in mind, the owners (perhaps represented by the chairman) or other senior managers hire a coach. The coach is then co-opted into management and may well have some input in the recruitment of the playing staff with whatever budget has been made available (in some cases, a director of football will play the primary role here). Errors of judgment may be made, for example, by the chairman (who may choose a lower quality coach to work with the more expensive players whom the club can then afford) or by the director of football (who may use his budget to hire a suboptimal balance of stars and journeymen or international and local players). Poor decisions at any level of management will prevent the club from reaching the level of performance (in terms of league points) that should be possible given its power and status. In our specification of Equation (2) previously, the $z_{i, t}$ (the technical decision variables) represent a selection of such technical decisions. Studying them would not yield any conclusions if the management team at every club operated with maximum efficiency because then each club would be achieving the level of sporting performance commensurate with its endowment of power.

Table 2 presents generalized likelihood-ratio tests of the null hypothesis that the inefficiency effects are absent from the model and that decision variables are jointly insignificant. A general result for all the specifications is that inefficiency effects are highly significant in both the Italian and the Chilean leagues.

Table 3 reports results from the estimation of the stochastic frontiers for the two leagues (for Italy, columns (2) to (4) relate to re-estimation in robustness tests reported later; the lead results are in column (1)). The core finding is from the estimation of $\gamma$ that suggests a more important role of stochastic shocks in managerial decisions in the Italian compared with the Chilean league.

Table 2. Tests of Hypotheses for Parameters of the Inefficiency Frontier in the Italian and Chilean Leagues

\begin{tabular}{|c|c|c|c|c|c|c|c|}
\hline & \multicolumn{5}{|c|}{ Italy } & \multicolumn{2}{|c|}{ Chile } \\
\hline & (1) & (2) & (3) & (4) & (5) & (1) & (5) \\
\hline $\begin{array}{l}\text { Null hypothes } \\
\text { Test statistic }\end{array}$ & $\begin{array}{c}0: \gamma=\delta_{0}= \\
181.99^{*}\end{array}$ & 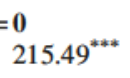 & $183.52^{* * *}$ & $183.70^{* * *}$ & $133.04^{* * *}$ & $39.33^{* * *}$ & $32.21^{*}$ \\
\hline $\begin{array}{l}\text { Null hypothes } \\
\text { Test statistic }\end{array}$ & $\begin{array}{c}: \boldsymbol{\delta}_{\mathbf{0}}=\ldots \\
157.72^{*}\end{array}$ & $205.38^{* * *}$ & $161.08^{* * *}$ & $159.3^{* * *}$ & $115.7^{* * *}$ & $39.32^{* * *}$ & $32.32^{*}$ \\
\hline
\end{tabular}

(1) Estimation including all teams in the top division. (2) Estimation excluding observations from seasons 2004/2005, 2005/2006 and 2006/ 2007. (3) Estimation similar to (1) but variable 'capital' refers to the capital of any Italian province. (4) Estimation similar to (1) but variable 'capital' refers to any of the four biggest Italian cities. (5) Estimation similar to (1) but including the variable "new manager" in the estima tion and dropping teams that was in the second division the previous year. ***,**and *denote rejection at $0.01,0.05$ and 0.10 significance level, respectively. 


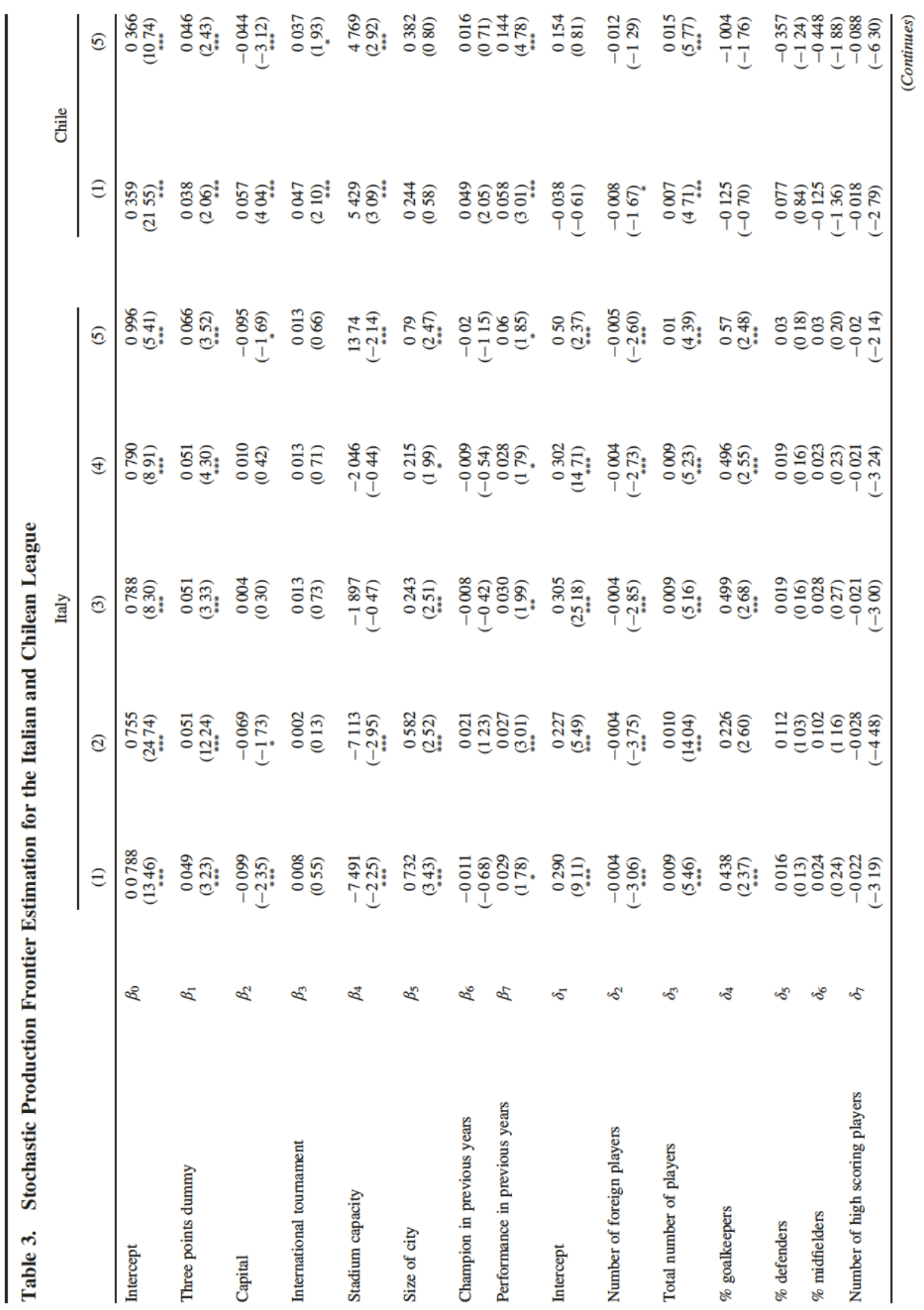







Among the resource variables, the results for Italy show that the size of a team's home city is indeed an important determinant of the level of achievement of a football club. However, the benefit from city size is mitigated by location in the capital city; this could reflect diminishing returns to city size in the sports sector (Buraimo et al., 2009), or the fact that, in the Italian context, the biggest cities usually host competing high level football clubs that split the market. Stadium capacity (for a given size of city) is shown to have a negative impact on performance. Possibly managers with a large number of seats to fill relative to the size of the local market will have to price tickets lower: with the inelastic demand claimed to prevail in sports markets in developed countries, this will imply depressed revenue compared with what would be expected given the size of the city. Results on these spatial variables are different in Chile. There population itself is not significant but location in Santiago de Chile assuredly is. This combination of results likely reflects that a high proportion of clubs is located in the capital, and, given they all have the same value for city size, this will prevent the importance of population size per se from being detected in the estimation. In general, some Chilean clubs may face stronger financial constraints and/or a lower demand by supporters and media to increase the capacity of the stadium, and therefore, it is not surprising that stadium size is a positive predictor of performance in this case. While results on these spatial variables display contrasts between Italy and Chile, the history variables yield similar findings: a history of achievement raises performance in the current period. Again, this is consistent with the importance of market size as clubs that were successful in the past will have collected more supporters on the way to the present.

Our technical decision variables test for effects from several individual categories of technical managerial decisions. The choice of coach is shown to matter substantially. For Italy, similar to Simmons and Frick (2008) for Germany, we find that the quality of the coach (as reflected in his career win-ratio) is important; but his length of experience has no independent role. Because it is inefficiency that is being modeled, the negative sign indicates that clubs who employ a coach with a better than average career record tend to be the clubs that are more efficient in converting status to sporting performance. The same is found in Chile. One of several possible explanations is that decision takers at some clubs undervalue coaching relative to player inputs. Note that we do not include a variable to account for the influence of a new manager (compared with the one who finished the previous season). The reason is that, for the Chilean league, we do not have information about the manager of teams playing in the second division the previous year, and here, we show a similar estimation in both countries for the purpose of comparison. However, when we run a similar estimation for Italy, including this variable, there are no significant changes in our results; the proportion of error variance due to technical inefficiencies is still significant $(0.928$ with a $t$-value of 12.22), and the variable new manager exerts a negative impact (but not significantly different from 0) on performance. This result accords with previous analysis by Tena and Forrest (2007), by using match level data, who suggest that a new manager has only a very small effect, and then only for a small number of matches (scapegoat hypothesis).

Players' wages account for the largest part of expenditure by professional sports teams, and it is clearly a key that whatever budget is available is spent judiciously. One trade-off clubs face is between the number of players on the roster and the average quality of players (higher quality players are likely to be more expensive), and a striking feature from Table 3 is the very high variance in squad size. In both countries, clubs with a below average squad size appear to be more efficient than those who opt for more players. Perhaps the former enjoy greater success because of substitution of quality for quantity, or it could be that players in a small squad benefit from having more playing time. Of course, it is also (just) possible that clubs who employ a higher number of personnel understand that this lowers expected performance but accept the fact because they are risk averse and, for example, want to guard against the adverse consequences of an exceptional number of injuries. The same remark qualifies the finding that a higher number of goalkeepers in the squad appears to be associated (in Italy) with lower efficiency. But the ratios of defenders and midfielders are not significant explanatory variables in either country. Therefore, the results do not point a way to increasing the efficiency of clubs by altering these proportions.

As an additional robustness test, we analyze the impact of including a new decision variable in the model, new coach that is defined as a dummy variable, which takes value 1 when the manager of the team at the beginning of the season is different from the one at the end of the previous season. In this case, we are obliged to drop observations from teams playing in the second division in the previous year as information about this variable was not available for teams in the Chilean 
Table 4. Stochastic Production Frontier Estimation for Different Measures of City Size

\begin{tabular}{|c|c|c|c|c|c|}
\hline & & & & & \\
\hline & & (1) & (2) & (1) & (2) \\
\hline Intercept & $\beta_{0}$ & $\begin{array}{c}0.76 \\
(17.32)\end{array}$ & $\begin{array}{c}0.78 \\
(9.28)\end{array}$ & $\begin{array}{c}0.38 \\
(12.87)\end{array}$ & $\begin{array}{c}0.39 \\
(21.49)\end{array}$ \\
\hline Three points dummy & $\beta_{1}$ & $\begin{array}{c}0.05 \\
(2.83) \\
* * *\end{array}$ & $\begin{array}{c}0.05 \\
(3.24)\end{array}$ & $\begin{array}{c}0.04 \\
(2.24)\end{array}$ & $\begin{array}{c}0.04 \\
(1.89)\end{array}$ \\
\hline Capital & $\beta_{2}$ & $\begin{array}{c}0.02 \\
(1.09)\end{array}$ & 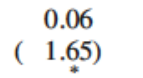 & $\begin{array}{c}0.05 \\
(3.56)\end{array}$ & $\begin{array}{c}0.06 \\
(3.91)\end{array}$ \\
\hline International tournament & $\beta_{3}$ & $\begin{array}{c}0.01 \\
(0.71)\end{array}$ & $\begin{array}{c}0.01 \\
(0.53)\end{array}$ & $\begin{array}{c}0.04 \\
(1.84)\end{array}$ & $\begin{array}{c}0.04 \\
(2.11)\end{array}$ \\
\hline Stadium capacity & $\beta_{4}$ & $\begin{array}{c}4.12 \\
(1.37)\end{array}$ & $\begin{array}{l}2.90 \\
(1.07)\end{array}$ & $\begin{array}{c}5.96 \\
(3.95)\end{array}$ & $\begin{array}{c}5.00 \\
(3.36)\end{array}$ \\
\hline Size of city & $\beta_{5}$ & $\begin{array}{l}0.000001 \\
(0.71)\end{array}$ & $\begin{array}{l}0.00002 \\
(2.77)\end{array}$ & $\begin{array}{l}0.00001 \\
(2.54)\end{array}$ & $\begin{array}{l}0.0003 \\
(1.54)\end{array}$ \\
\hline Champion in previous years & $\beta_{6}$ & $\begin{array}{l}0.01 \\
(0.49)\end{array}$ & $\begin{array}{l}0.01 \\
\left(\begin{array}{l}0.83)\end{array}\right)\end{array}$ & $\begin{array}{c}0.03 \\
(1.37)\end{array}$ & $\begin{array}{c}0.04 \\
(1.61)\end{array}$ \\
\hline Performance in previous years & $\beta_{7}$ & $\begin{array}{c}0.03 \\
(1.63)\end{array}$ & $\begin{array}{c}0.03 \\
(1.76)\end{array}$ & $\begin{array}{c}0.06 \\
(2.88)\end{array}$ & $\begin{array}{c}0.07 \\
(3.52)\end{array}$ \\
\hline Intercept & $\delta_{1}$ & $\begin{array}{c}0.29 \\
(4.60)\end{array}$ & $\begin{array}{c}0.28 \\
(6.70)\end{array}$ & 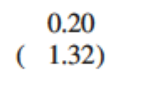 & $\begin{array}{l}0.14 \\
(0.97)\end{array}$ \\
\hline Number of foreign players & $\delta_{2}$ & $\begin{array}{l}0.004 \\
\left(\begin{array}{c}2.59) \\
* * *\end{array}\right.\end{array}$ & $\begin{array}{l}0.004 \\
(2.57)\end{array}$ & $\begin{array}{l}0.02 \\
\left(\begin{array}{c}2.79 \\
* * *\end{array}\right)\end{array}$ & $\begin{array}{l}0.02 \\
\left(\begin{array}{c}2.87 \\
* * *\end{array}\right)\end{array}$ \\
\hline Total number of players & $\delta_{3}$ & $\begin{array}{c}0.01 \\
(5.22)\end{array}$ & $\begin{array}{c}0.01 \\
(5.38)\end{array}$ & $\begin{array}{c}0.01 \\
(5.43)\end{array}$ & $\begin{array}{c}0.01 \\
(6.13)\end{array}$ \\
\hline$\%$ goalkeepers & $\delta_{4}$ & $\begin{array}{c}0.45 \\
(2.17)\end{array}$ & $\begin{array}{c}0.44 \\
(2.26)\end{array}$ & $\begin{array}{l}0.35 \\
\left(\begin{array}{l}1.06 \\
)\end{array}\right)\end{array}$ & $\begin{array}{l}0.46 \\
(1.17)\end{array}$ \\
\hline$\%$ defenders & $\delta_{5}$ & $\begin{array}{c}0.03 \\
(0.21)\end{array}$ & $\begin{array}{c}0.02 \\
(0.18)\end{array}$ & $\begin{array}{c}0.27 \\
(1.23)\end{array}$ & $\begin{array}{l}0.14 \\
(0.63)\end{array}$ \\
\hline$\%$ midfielders & $\delta_{6}$ & $\begin{array}{c}0.04 \\
(0.39)\end{array}$ & $\begin{array}{c}0.03 \\
(0.31)\end{array}$ & $\begin{array}{l}0.02 \\
\left(\begin{array}{l}0.11)\end{array}\right)\end{array}$ & $\begin{array}{l}0.05 \\
(0.30)\end{array}$ \\
\hline Number of high scoring players & $\delta_{7}$ & $\begin{array}{c}0.02 \\
\left(\begin{array}{c}2.94) \\
* * * 2\end{array}\right)\end{array}$ & $\begin{array}{c}0.02 \\
(3.04)\end{array}$ & $\begin{array}{l}0.05 \\
\left(\begin{array}{c}4.17 \\
* * *\end{array}\right)\end{array}$ & $\begin{array}{l}0.04 \\
\left(\begin{array}{l}3.19) \\
* * *\end{array}\right)\end{array}$ \\
\hline Manager quality & $\delta_{8}$ & 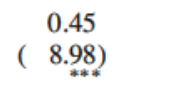 & $\begin{array}{c}0.44 \\
(8.93)\end{array}$ & $\begin{array}{l}0.18 \\
(3.43)\end{array}$ & $\begin{array}{l}0.19 \\
\left(\begin{array}{c}2.67) \\
* * *\end{array}\right)\end{array}$ \\
\hline Manager experience & $\delta_{9}$ & 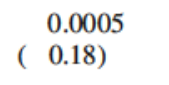 & $\begin{array}{l}0.0006 \\
\left(\begin{array}{l}0.19)\end{array}\right)\end{array}$ & $\begin{array}{c}0.01 \\
(2.99)\end{array}$ & $\begin{array}{c}0.01 \\
(3.29)\end{array}$ \\
\hline Foreign manager & $\delta_{10}$ & $\begin{array}{c}0.01 \\
(0.86)\end{array}$ & $\begin{array}{c}0.01 \\
(1.00)\end{array}$ & $\begin{array}{l}0.02 \\
\left(\begin{array}{l}0.97)\end{array}\right)\end{array}$ & $\begin{array}{l}0.01 \\
(0.63)\end{array}$ \\
\hline Composed error variance & $\sigma^{2}$ & $\begin{array}{c}0.01 \\
(12.46)\end{array}$ & $\begin{array}{c}0.01 \\
(12.75)\end{array}$ & $\begin{array}{c}0.01 \\
(8.98)\end{array}$ & $\begin{array}{c}0.01 \\
(9.55)\end{array}$ \\
\hline $\begin{array}{l}\text { Proportion of error variance due to } \\
\text { technical inefficiencies }\end{array}$ & $\gamma$ & $\begin{array}{c}1.00 \\
(3.83)\end{array}$ & $\begin{array}{c}1.00 \\
(1.86)\end{array}$ & $\begin{array}{c}0.11 \\
(0.95)\end{array}$ & $\begin{array}{c}0.10 \\
(1.47)\end{array}$ \\
\hline $\begin{array}{l}\text { Log likelihood } \\
\text { Observations }\end{array}$ & & $\begin{array}{l}337.34 \\
296\end{array}$ & $\begin{array}{l}340.43 \\
296\end{array}$ & $\begin{array}{l}272.71 \\
274\end{array}$ & $\begin{array}{l}271.23 \\
274\end{array}$ \\
\hline
\end{tabular}

All estimation includes the baseline specification. Estimation (1) considers per capita income of the city and estimation (2) the total income of the city as the measure of city size.

***, **and *denote rejection at $0.01,0.05$ and 0.10 significance level, respectively. 
league. Results of this estimation reflect that now the efficiency hypothesis is rejected in both cases because the Chilean league proves to be particularly inefficient in replacing old managers. However, also in this case the proportion of variance due to technical inefficiencies (and also the associated $t$-statistics) is substantially larger in the Italian compared with the Chilean league.

From the results, a particularly tricky decision for football clubs (as will be the case for managers in other creative industries, such as opera or research) is the proportion of resources to be used on star performers. In football, these are usually successful strikers, defined here by the variable 'number of high scoring players'. This attracts a negative coefficient estimate for both countries, implying that clubs that choose to employ none or only a small number will fail to reach the production frontier. The implication that some clubs undervalue genuine strikers is weakened, of course, if there are labor market imperfections, which restrict their movement away from their current clubs.

The degree of efficiency shown by a club in the Italian League appears also to be associated with its propensity to recruit foreign players compared with other clubs. Just as Kahane (2005) demonstrated that clubs, which displayed a reluctance to employ francophone ice hockey players tended to pay a price in terms of lower levels of performance, so here a club with a below average number of foreigners is shown to fare worse as a result. ${ }^{6}$ However, no significant effect is found in Chile, probably because its weak league cannot attract quality foreign footballers who would provide better value than local players.

Broadly, the results of the model imply that, while historical and geographical variables intended to capture market size play their expected roles in both Italy and Chile, the degree of technical inefficiency is lower magnitude in Chile. To test the robustness of these results, we analyze now the implications of two different set of experiments. These estimations are also shown in Table 3. More specifically, our first group of experiments refers to possible distortions resulting from penalties imposed on clubs for illegal activities (mainly match fixing scandals) in the Italian league during seasons 2004/2005, 2005/2006 and 2006/2007. We eliminate these three seasons from the sample and estimate the model again. Main results were robust to this experiment. ${ }^{7}$

The model was also estimated for different definitions of variables for the Italian case. More specifically, we consider a dummy variable that takes value 1 when the team is located in any of the biggest four Italian cities:
Rome, Milan, Naples and Turin. Conclusions are not affected in either case, and the null of managerial efficiency could be rejected in both instances at the $1 \%$ level. ${ }^{8}$

Another set of experiments related to the inclusion of size of the city. As discussed earlier, this is a potentially controversial indicator as it is a proxy variable for market size. We experimented with some alternative definitions of market size, such as the number of inhabitants in the city divided by the number of clubs. However this variable turned out not to be significant, which suggests at least in the long run, the size of the market in a given city is not exogenously given but it could be stimulated by the competition of rival neighbor teams. We also studied whether some alternative variables related not only to the number of citizens but also to income could have a significant impact on performance. More specifically, we ran the baseline estimation but replaced the number of citizens by the following: (1) income per-capita in the city and (2) total income in the city. Results of this estimation are reported in Table 4. Note that the main conclusions of the paper stand, and, interestingly, per-capita income is significant only for Chile, and total income is significant only for Italy. This suggests that the relevant market size indicator for a football team could be different for a developed and a developing country. Indeed it is plausible to assume that a minimum level of income is needed to become a football fan, and once this threshold is surpassed, football stop being a luxury good, and therefore, total demand mainly depends on the number of potential supporters.

This paper analyzes the relationship between resource inputs and managerial efficiency in firms by the estimation of stochastic production frontiers for the top divisions in Chilean and Italian football. Unlike previous research, we focus not only on coach efficiency but also on the ability of the whole organization to transform its potential power over resources to the best possible outcome in terms of league points. Results indicate the presence of technical inefficiencies in both cases, but technical inefficiencies play a more important role in the Italian League in a way that is consistent with the theoretical explanation provided in Section 2 that suggests that managerial decisions provide a more important role when firms do not face strong restrictions imposed by the size of the market or by financial variables. Although the comparison of two extreme cases is a novel aspect of our paper, a 
more complete and definitive analysis should be based on the comparison of national leagues in a number of different countries. This work is left for further research.

Other future lines of research are suggested by this work. First, an important branch of the sports literature is devoted to studying the factors that explain differences in competitive balance; see, for example, Butler (1995), Flores et al. (2010) and Horowitz (1997). Given that our results show how the impact of different variables on results performance depends on indicators of geography and history, as well as managerial decisions undertaken by the clubs, it would be interesting to study the relative importance of these variables in order to explain differences in competitive balance for sport competitions. Further, given that power indicators are not fixed in time but could be affected by market fluctuations, as well as by changes in regulations, the model provides insight about how management effort and the structure of the competition will be affected by these changes.

Finally, it is critical to understand why the relative importance of power depends on the structure of national competitions. Our results suggest that, in leagues with smaller and simpler clubs, power variables explain a more important share of results than in the case of strong leagues, whereas the opposite holds for managerial decision variables. Developing a theoretical model, which provides an explanation for this result is an issue to be explored in future research.

\section{Acknowledgements}

We are grateful to two anonymous referees for incisive suggestions and participants at the First European Conference in Sport Economics in Paris for helpful comments. We would also like to thank A. M. Palomba and M. Iturrieta for assistance with data compilation and to the Centro de Estudios del Deporte (CEPED) for providing us with valuable information on the Chilean League. The second and third authors acknowledge the financial support of MIUR.PRIN 2008 and Fondazione Banco di Sardegna.

\section{NOTES}

1. Note that the analysis period in this paper does not include the current financial economic crisis that had a more impor tant effect on Europe than on Latin American countries.

2. Although we do not have budget information for all the teams in the Chilean league we know, for example, that the three highest transfer fees paid in the history of the Chilean football were for Macnelly Torres, USD $2 \mathrm{mil}$ lions in 2008, Nelson Cabrera, USD 1 million in 2008 and Mauricio Victorino USD 800,000 in 2009. These re cord Chilean transfer fees are in fact similar in magnitude to those routinely paid every year by the smallest clubs in the Italian Serie A.
3. The Appendix formally sets out the specification of the theoretical model.

4. Note that this estimation would be consistent with the log transformation of a Cobb Douglas functional form such as $\exp \left(Y_{i, t}\right)=\prod_{i{ }_{1}}^{K}\left(\exp \left(x_{i, t}\right)\right)^{\beta_{i *}} \exp \left(v_{i, t}+v_{i, t}\right)$ where $x_{i, t}=1$, and $\beta_{i}$ is the $i$ th component of vector $\beta$.

5. In addition, it is plausible to assume that, for the same salary, a footballer would prefer to play for a stronger team. Stronger clubs therefore need to pay less for a given quality of squad, and this would produce an addi tional distortion in the use of salary as an indicator of power.

6. Recent papers have highlighted the beneficial effects of foreign players in increasing the probability of success of the national team (Alvarez et al., 2011 report this effect for the case of basketball and attribute it to spillover effects that raise the ability level of domestic players, and Binder and Findlay (2012) find a positive effect, but only in the short run, for European football) and in increasing or not harming the level of competitiveness in domestic leagues, Flores et al. (2010), Binder and Findlay (2012) and Frick (2009).

7. Main results are not altered when instead of dropping the three seasons affected by the Moggi scandal we just elim inate the teams involved in the practice of fixing matches from the regression; see Boeri and Severgnini (2011).

8. We also tried with an ad hoc definition of 'capital' for Italy: the city of Milan where two of the most important football teams play, Internazionale di Milano and A.C. Milan. However, this variable was not significant at conventional levels.

\section{APPENDIX}

The profit function is

$V_{i}\left(k_{i}, s_{i}\right)=\Pi_{i}\left(k_{i}, s_{i}\right)-C_{i}\left(k_{i}, s_{i}\right)$.

Revenue $\Pi_{i}\left(k_{i}, s_{i}\right)$ is composed of two parts, one certain and one uncertain. Formally, we have $\Pi_{i}\left(k_{i}, s_{i}\right)=$ $D k_{i}+F p_{i}$. We assume that $F>D$.

In particular, we denote by $p_{i}$ the probability of success in the industry by firm $\mathrm{i}$ and assume that $p_{i}$ depends positively on its own resource investment $\left(s_{i}\right)$ and on managerial effort $\left(k_{i}\right)$, and negatively on the level of capital investment and managerial effort undertaken by its competitor, $\left(k_{j}, s_{j}\right)$. In particular, we give to this probability the following functional form:

$p_{i}=\frac{1}{2}+\frac{1}{2}\left[\left(s_{i}-s_{j}\right)+\left(k_{i}-k_{j}\right)\right]$

with $p_{i} \in[0,1]$ and $p_{1}+p_{2}=1$

Regarding the cost function, it is assumed that cost depends on the club's own resources, $\left(k_{i}\right)$, and effort, $\left(s_{i}\right)$, as well as on the level of resource investment undertaken by the rival firm in the industry, $\left(k_{j}\right)$. Formally, we suppose that $C_{i}=\left(k_{i}+k_{j}\right) k_{i}+s_{i}\left(s_{i}+k_{i}\right)$ with $i=1,2$ and $j \neq i$. 
In the unconstrained case, clubs 1 and 2 decide their respective levels of investment and effort. By equalizing the marginal returns of clubs $i$ and $j$, we find that

$$
\begin{aligned}
& k^{*}{ }_{i}=\frac{1}{2}\left(D-k_{j}^{*}\right)+\frac{1}{4}\left(F-2 s_{i}^{*}\right) \\
& s_{i}^{*}=\frac{1}{4}\left(F-2 k_{i}^{*}\right) .
\end{aligned}
$$

\section{REFERENCES}

Aigner DJ, Lovell CAK, Schmidt P. 1977. Formulation and estimation of stochastic frontier production function models. Journal of Econometrics 6: 2137.

Alvarez J, Forrest D, Sanz I, Tena JD. 2011. Impact of importing foreign talent on performance levels of local co workers. Labour Economics 18: 287296.

Battese GE, Coelli T. 1993. A stochastic frontier production function incorporating a model for technical inefficiency effects, Working Papers in Econometrics and Applied Statistics. N.69. University of New England.

Battese GE, Coelli T. 1995. A model for technical ineffi ciency effects in a stochastic frontier production for panel data. Empirical Economics 20: 325332.

Binder JJ, Findlay M. 2012. The effects of Bosman ruling on national and club teams in Europe. Journal of Sport Economics 13: 107129.

Boeri T, Severgnini B. 2011. Match rigging and the career concerns of referees. Labour Economics 18: 349359.

Buraimo B, Forrest D, Simmons R. 2007. Freedom of entry, market size and competitive outcome: evidence from English soccer. Southern Economic Journal 74: 204213.

Buraimo B, Forrest D, Simmons R. 2009. Insights for clubs from modelling match attendance in football. Journal of the Operational Research Society 60: 147155.

Butler MR. 1995. Competitive balance in Major League Baseball. The American Economist 39: 4652.
Coelli T. 1996. A guide to FRONTIER 4.1: a computer pro gram for stochastic frontier production and cost function estimation, CEPA, Working Paper 96/08. University of New England.

El Hodiri M, Quirk J. 1971. An economic model of a profes sional sports league. Journal of Political Economy 79: 13021319.

Flores R, Forrest D, Tena JD. 2010. Impact on competitive balance from allowing foreign players in a sport league: evidence from European soccer. Kyklos 63: 546557.

Frick B. 2009. Globalization and factor mobility: the impact of "Bosman Ruling" on player migration in professional soccer. Journal of Sports Economics 10: 8106.

Haan M, Koning RH, van Witteloostuijn A. 2002. Market forces in European soccer. CCSO Working Paper 200211, University of Groningen, CCSO Centre for Economic Research.

Hofler R, Payne J. 2006. Efficiency in the National Basket ball Association: a stochastic frontier approach with panel data. Managerial and Decision Economics 27: 279285.

Horowitz I. 1997. The increasing competitive balance in Major League Baseball. Review of Industrial Organiza tion 12: 373388

Kahane L. 2005. Production efficiency and discriminatory hiring practices in the National Hockey League. A stochas tic frontier approach. Review of Industrial Organization 27: 4771 .

Késenne S. 2007. The peculiar international economics of professional football in Europe, Scottish Journal of Polit ical Economy 54: 388399.

Mas Colell AW, Michael D, Green JR. 1995. Microeco nomic Theory. Oxford University Press: Oxford, UK.

Meeusen W, Van den Broeck J. 1977. Efficiency estimation from Cobb Douglas production functions with composed error. International Economic Review 18: 435444.

Paolini D, Tena JD. 2012. Institutional complexity and man agerial efficiency: a simple model, CRENoS 2012/23.

Simmons R, Frick B. 2008. The impact of managerial qual ity on organizational performance: evidence from German soccer. Managerial and Decision Economics 29: 593600.

Tena JD, Forrest D. 2007. Within season dismissal of foot ball coaches: causes and consequences. European Journal of Operational Research 181: 362373. 